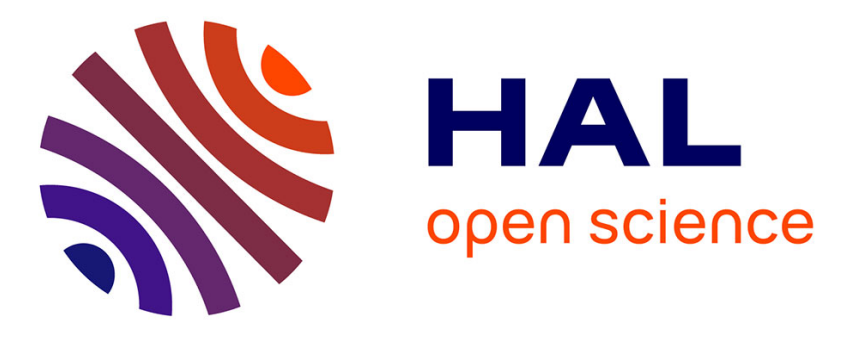

\title{
Extracytoplasmic function sigma factors in Pseudomonas aeruginosa
}

Sylvie Chevalier, Emeline Bouffartigues, Alexis Bazire, Ali Tahrioui, Rachel Duchesne, Damien Tortuel, Olivier Maillot, Thomas Clamens, Nicole Orange, Marc G.J. Feuilloley, et al.

\section{To cite this version:}

Sylvie Chevalier, Emeline Bouffartigues, Alexis Bazire, Ali Tahrioui, Rachel Duchesne, et al.. Extracytoplasmic function sigma factors in Pseudomonas aeruginosa. Biochimica et Biophysica Acta Gene Regulatory Mechanisms , 2018, 10.1016/j.bbagrm.2018.04.008 . hal-01788719

\section{HAL Id: hal-01788719 https://hal.science/hal-01788719}

Submitted on 21 Dec 2021

HAL is a multi-disciplinary open access archive for the deposit and dissemination of scientific research documents, whether they are published or not. The documents may come from teaching and research institutions in France or abroad, or from public or private research centers.
L'archive ouverte pluridisciplinaire HAL, est destinée au dépôt et à la diffusion de documents scientifiques de niveau recherche, publiés ou non, émanant des établissements d'enseignement et de recherche français ou étrangers, des laboratoires publics ou privés.

\section{(ㄷ)(1) $\$$}

Distributed under a Creative Commons Attribution - NonCommerciall 4.0 International 


\section{Transcriptional regulation of development in heterocyst-forming 2 cyanobacteria}

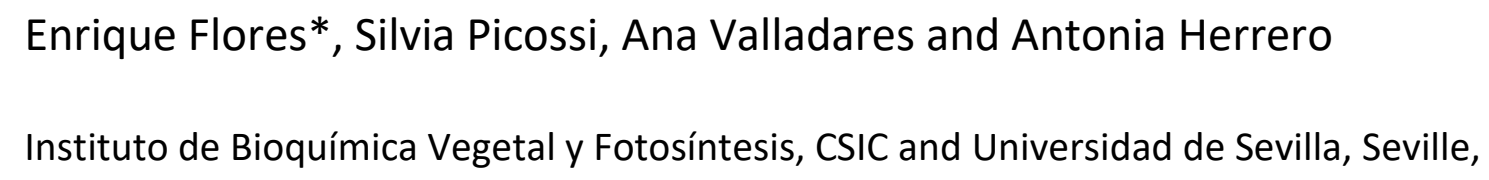

*E-mail address: eflores@ibvf.csic.es

11

\section{ABSTRACT}

Filamentous, heterocyst-forming cyanobacteria are among the simplest multicellular systems in Nature. In the absence of combined nitrogen, the filaments consist of vegetative cells that fix $\mathrm{CO}_{2}$ through oxygenic photosynthesis and micro-oxic heterocysts specialized for the fixation of $\mathrm{N}_{2}$ in a proportion of about 10 to 1 . The development of a heterocyst-containing filament involves differentiation of vegetative cells into heterocysts in a process that requires a distinct gene expression program. Two transcription factors are strictly required, the CRP-family NtcA and HetR. NtcA directly activates the expression of multiple genes during heterocyst differentiation -in some cases assisted by coactivators including HetR- and in mature heterocysts, whereas HetR is needed to build high NtcA levels in differentiating heterocysts and directly activates some particular genes. A few other regulators of gene expression

30 participate at specific differentiation steps, and a specific transcription factor, $\mathrm{CnfR}$, activates

31 nif gene expression under the micro-oxic conditions of the heterocyst. 


\section{Introduction}

Multicellularity is a form of organization widely found in living organisms including evidently eukaryotes but also prokaryotes. Two properties characterize multicellularity: cell-cell binding and cell-cell communication. Additionally, organisms take advantage of multicellularity to specialize cells in different functions, so that cellular differentiation is another hallmark of multicellularity. Proterozoic microfossils frequently show a multicellular form, and filamentous cyanobacteria showing cellular differentiation have been traced back to about $2.45-2.1$ billion years ago [1]. Cyanobacteria are a phylogenetically coherent group of organisms characterized by performing oxygenic photosynthesis, which allows a mainly photoautotrophic mode of growth [2]. Additionally, many cyanobacteria can fix atmospheric $\mathrm{N}_{2}$, making these organisms capable to grow with very simple nutritional sources -air and water with a few mineral salts. However, because the $\mathrm{N}_{2}$-fixation machinery is very sensitive to oxygen [3], cyanobacteria need to separate $\mathrm{N}_{2}$ fixation from oxygenic photosynthesis. Whereas some unicellular and filamentous cyanobacteria separate these two incompatible processes temporally, restricting $\mathrm{N}_{2}$ fixation to the dark period of diel cycles [3], some filamentous cyanobacteria form cells specialized for $\mathrm{N}_{2}$ fixation. Thus, in filaments of cells that fix $\mathrm{CO}_{2}$ through oxygenic photosynthesis, some of these cells (usually less than $10 \%$ ) differentiate into $\mathrm{N}_{2}$-fixing heterocysts when no combined nitrogen is available [4]. Other developmental options found in some heterocyst-forming cyanobacteria include the differentiation of akinetes, a type of spores that resist drought and cold, and the production of hormogonia, short motile filaments frequently made of small-sized cells that serve a dispersal function $[5$, 6]. Knowledge of the transcriptional regulation for the differentiation of akinetes and hormogonia is however scarce [6]. This review will focus on the transcriptional regulatory mechanisms that operate in heterocyst differentiation. We shall first briefly introduce the structure of the cyanobacterial filament and the morphology and biochemistry of the heterocyst, then describe the mechanisms of regulation of gene expression that operate during the process of differentiation and in the mature $\mathrm{N}_{2}$-fixing heterocyst, and finally discuss the early regulation that leads to a defined pattern of heterocyst distribution in the filament.

\section{Cyanobacterial filaments and heterocysts}

Cyanobacteria of the order Nostocales -taxonomic section IV in the classification of Rippka et al. [2]- are characterized by their ability to produce heterocysts when they lack a source of combined nitrogen [2]. These cyanobacteria grow as filaments that can be hundreds of cells 
long, and heterocysts can be found intercalary or at the end in the filaments, although some strains make only terminal heterocysts [2]. Heterocysts are terminally differentiated cells, and commitment to complete differentiation is established after the spatial distribution pattern of heterocysts has already been settled $[7,8]$.

\subsection{Structure of the cyanobacterial filament}

The cyanobacteria are diderm bacteria, i.e., they bear a Gram-negative type of cell envelope. The cells in a cyanobacterial filament are surrounded by their cytoplasmic membrane and peptidoglycan layer(s), but the outer membrane does not enter into the septa between consecutive cells and, therefore, is continuous along the filament [9]. This implies that the periplasm -the space that lies between the cytoplasmic and outer membranes and contains the peptidoglycan- is also continuous and may be a communication conduit between the cells in the filament [10]. Consecutive cells in the filament are also joined by proteinaceous structures known as septal junctions $[9,11]$, which appear to traverse the septal peptidoglycan through perforations known as nanopores $[12,13]$. These perforations are drilled in the peptidoglycan by AmiC-type amidases $[12,14]$. In the model heterocyst-forming strain Anabaena sp. PCC 7120 (hereafter Anabaena), the SepJ (a.k.a. FraG), FraC and FraD proteins are localized at the cell poles in the intercellular septa of the filament $[15,16]$. They are membrane proteins that, in the case of SepJ and FraD, have long extra-membrane sections that appear to be located outside of the cells in the intercellular septa, and at least SepJ is known to form multimers $[17,18]$. Hence, they are candidate components of the septal junctions (see below).

\subsection{Heterocyst morphology}

Under the light microscope, the heterocysts are seen larger than the vegetative cells and show two refractile bodies at their poles (just one, proximal to the vegetative cells, in the case of terminal heterocysts) (Fig. 1A). Under the electron microscope, differences become evident in the global form of the heterocyst, in its envelope, and in its cytoplasm (Fig. 1B). The heterocyst poles adjacent to vegetative cells take a narrow form known as "neck", which makes the area of contact between heterocysts and vegetative cells smaller than that between vegetative cells. The cell envelope contains extra material that is deposited outside the outer membrane and consists of an inner glycolipid (heterocyst-specific glycolipid, Hgl) layer and an outer polysaccharide (heterocyst envelope polysaccharide, Hep) layer. Three characteristics distinguish the heterocyst cytoplasm from the vegetative cell cytoplasm [6]: (i) intracellular membranes are reorganized forming a structure known as "honeycomb" around the 
103 heterocyst poles; (ii) glycogen granules and carboxysomes (the intracellular micro104 compartments that contain ribulose bisphosphate carboxylase/oxygenase [RuBisCO, the $\mathrm{CO}_{2}$ 105 fixing enzyme]) disappear; and (iii) a large granule made of cyanophycin (multi-L-arginyl-poly 106 [L-aspartic acid]) is deposited at the heterocyst poles adjacent to vegetative cells -these 107 granules correspond to the refractile bodies observed by light microscopy.

\subsection{Heterocyst biochemistry}

110 The heterocyst has evolved to become a $\mathrm{N}_{2}$-fixing factory. Hence, an essential goal of its 111 biochemistry is to keep a micro-oxic environment appropriate for the expression and function 112 of the $\mathrm{N}_{2}$-fixing enzyme, nitrogenase, and accessory proteins. First, importantly, the oxygen113 releasing photosystem II (PSII) is non-functional in the heterocyst (reviewed in [19]). Second, 114 the extra envelope described above restricts gas diffusion contributing to reduce the amount 115 of oxygen that enters in the heterocyst as air $\left(78 \% \mathrm{~N}_{2}, 21 \% \mathrm{O}_{2}\right)$ [20]; indeed, $\mathrm{O}_{2}$ has been 116 suggested to enter the heterocyst mainly through the vegetative cell-heterocyst connections

117 [20]. Third, dedicated terminal respiratory oxidases located in the honeycomb membranes and

118 cytoplasmic flavodiiron proteins consume $\mathrm{O}_{2}$ contributing to create a micro-oxic environment

$119[21,22]$. The nitrogenase reaction consumes high amounts of ATP and reductant, and the 120 heterocyst keeps an electron transport chain and PSI activity that support 121 photophosphorylation and the reduction of ferredoxin that can provide nitrogenase with 122 electrons [19].

123 In the heterocyst, dinitrogen is reduced by the nitrogenase complex producing 124 ammonium (and hydrogen as a byproduct). The ammonium resulting from the $\mathrm{N}_{2}$-fixing 125 reaction is incorporated by glutamine synthetase into glutamate producing glutamine [23]. 126 Glutamine is, at least in part, transferred to vegetative cells in exchange for glutamate, which 127 is not synthesized at high levels in the heterocyst [24, 25]. Further anabolic nitrogen 128 metabolism in the heterocyst includes the biosynthesis of aspartate and arginine, which are 129 incorporated by cyanophycin synthetase into cyanophycin that serves as a dynamic nitrogen 130 reservoir $[26,27]$. In addition to glutamine, $\beta$-aspartyl arginine, the product of cyanophycin 131 degradation by cyanophycinase, is transferred to vegetative cells, in which $\beta$-aspartyl arginine 132 is hydrolyzed by isoaspartyl dipeptidase releasing aspartate and arginine [28]. Hence, both 133 glutamine and $\beta$-aspartyl arginine serve as nitrogenous nutrients for the vegetative cells. In 134 turn, because the heterocyst does not accomplish the photosynthetic fixation of $\mathrm{CO}_{2}$, the 135 vegetative cells provide the heterocysts with reduced carbon in the form of a sugar, sucrose, 136 that in Anabaena is split by an invertase -InvB- producing glucose and fructose, which 
137 support heterocyst metabolism [29, 30]. This exchange of reduced carbon by fixed nitrogen is

138 at the basis of the multicellular behavior of heterocyst-forming cyanobacteria.

2.4. Intercellular molecular exchange

141 During heterocyst differentiation and in the diazotrophic filament, regulators and metabolites

142 are transferred between cells. Intercellular molecular exchange in filamentous cyanobacteria

143 has been probed with fluorescent markers including calcein, 5-carboxyfluorescein and the

144 sucrose analog esculin [13, 31, 32]. The transfer has properties of simple diffusion, indicating

145 the existence of direct connections between adjacent cells [31, 32]. Mutants of Anabaena

146 lacking the septal proteins SepJ or FraC and FraD are impaired in the intercellular transfer of

147 those fluorescent markers and make less nanopores than the wild type, suggesting that these

148 proteins contribute to the formation of the septal junctions [13, 31]. Differences in the

149 impairment of transfer of the various fluorescent markers in different mutants have suggested

150 the existence of functionally-discernible SepJ- and FraCD-related septal junctions [13, 17].

151 Important for our discussion here is that septal junction complexes in the vegetative

152 cell/heterocyst septa may have specific characteristics as compared to those in vegetative

153 cell/vegetative cell septa. Thus, these structures appear to be longer in the former than in the

154 latter [33], and the SepJ protein visualized as a SepJ-GFP fusion is seen as a single fluorescent

155 spot between vegetative cells and as a double spot in the vegetative cell/heterocyst septa,

156 implying a more spread localization in the latter than in the former [11].

3. Key transcription factors and transcriptional regulation mechanisms

160 Two genes whose inactivation completely abolish heterocyst differentiation are ntcA [34, 35] 161 and hetR [36]. Whereas NtcA is a global regulatory transcription factor of cyanobacteria mediating responses to variations in the $\mathrm{C}$-to- $\mathrm{N}$ balance of the cells, HetR is a transcription factor specifically found in filamentous cyanobacteria whose best-known role is in cell differentiation.

NtcA is a cyanobacterial transcription factor that orchestrates the genetic responses to the Cto- $\mathrm{N}$ balance by directly regulating the expression of multiple genes involved in pathways for nitrogen assimilation, but also of a number of other metabolic pathways [37, 38]. Indeed, by means of chromatin-immunoprecipitation assays performed in Anabaena, an extraordinarily 
171 large number of NtcA-binding sites on DNA were identified that could be ascribed to more 172 than 2,000 genes [38]. Besides genes involved in nitrogen scavenging and $\mathrm{N}_{2}$ fixation, the $\mathrm{NtcA}$ 173 targets included genes involved in DNA metabolism, transcription and translation, central 174 metabolism and, remarkably, many predicted regulatory genes, which should extend the range 175 of NtcA-influenced cellular processes. NtcA belongs to the CRP ( $\underline{c}$ AMP receptor protein) family 176 of transcriptional regulators, presenting a domain architecture similar to that of the well177 characterized $E$. coli CRP protein, including an $\mathrm{N}$-terminal $\beta$-roll fold, which in CRP 178 accommodates the effector CAMP, a central long dimerization helix and a C-terminal helix179 turn-helix (HTH) motif for interaction with DNA [39] (Fig. 2A). These regulators are dimeric 180 proteins, so that each subunit interacts with half of a palindromic recognition sequence in 181 DNA.

182 NtcA can act as a transcriptional activator or repressor. For both activities, the NtcA 183 dimer binds to palindromic DNA sites including the consensus sequence GTAN $\operatorname{TAC}_{8}$ [37, 38]. In 184 many NtcA-activated promoters an NtcA-binding site is found separated by ca. 22 bp from a 18510 promoter determinant of consensus sequence $\operatorname{TAN}_{3} \mathrm{~T}$, thus conforming to the so-called 186 Class II bacterial activated promoters, in which the regulator binds in place of a missing or 187 degenerated -35 determinant. This promoter structure is frequently found in genes of 188 unicellular cyanobacteria and, in heterocyst-forming strains, in vegetative cell-expressed genes 189 as well as in genes expressed in mature heterocysts [40]. Besides this, NtcA can activate gene 190 expression from DNA sites centered further upstream the -35 position, conforming to Class I 191 activated promoters, or from promoters with very degenerated NtcA-binding sites, which are 192 generally activated during heterocyst differentiation [41]. Finally, repression by NtcA has been 193 shown involving binding sites downstream from promoter determinants, overlapping the -10 194 box or even within the regulated ORF [41].

195 Regarding metabolic signals, NtcA activity is influenced by 2-oxoglutarate (2-OG) [42].

196 Because cyanobacteria lack the enzyme 2-oxoglutarate dehydrogenase, the 2-OG cellular 197 levels depend on its synthesis during $\mathrm{CO}_{2}$ fixation and its consumption mainly to form 198 glutamate by the glutamine synthetase/glutamate synthase pathway, thus representing an 199 indicator of the cellular C-to-N balance [40]. Indeed, 2-OG has been shown to increase the 200 binding of NtcA to DNA in many regulated promoters in vitro, although in contrast to CRP, 201 NtcA can interact with DNA in the absence of the effector (see e.g. [37, 42, 43]). Structurally, 202 the positive effect of 2-OG in binding is explained by its effect on dimer stabilization by 203 decreasing the distance between the dimerization helices of each subunit, which in turn 204 repositions the two second helices in the HTH DNA-binding domains, making the global conformation more suitable for interaction with DNA [39]. In the absence of the effector, the 
NtcA apo-protein already presents in its DNA-binding domain some exposed positively-charged residues that represent a DNA-binding patch. In addition, the conformation of the last helices in this domain allows some interaction with DNA, whereas these helices are buried in the apoCRP [39].

Whereas a positive effect of 2-OG on NtcA binding to DNA in vitro has been found in all types of NtcA-activated promoters, although at variable extents, an additional and stringent requirement for 2-OG has been found for the step of promoter melting to form the tripartite

213 NtcA-RNA polymerase-DNA open promoter complex, and thus for transcript production, at

214 Class II NtcA-activated promoters [43]. However, no specific structural information is available

215 for this 2-OG effect, although it is reminiscent of that of CAMP during Class II activation by CRP.

216 Finally, the intrinsic capacity of NtcA to interact with DNA may be important for its action as a

217 repressor under physiological conditions that determine low 2-OG levels. This appears to occur

218 in the $c m p R$ gene (encoding a LysR-type regulator of a bicarbonate transporter operon), which

219 under conditions that determine low 2-OG levels is expressed at higher levels in an ntcA mutant than in the wild type [44].

\subsection{HetR}

For many years considered as a heterocyst-specific regulator, evidence is recently accumulating in support of HetR activity also in undifferentiated cells, consistent with the presence of HetR in non-heterocystous cyanobacteria as well as in heterocyst formers [45]. HetR is required for the expression of multiple genes involved in heterocyst differentiation, and binding of HetR to DNA from the promoter region of a few of them has been detected in vitro, including sequences from the promoters of hetR, patS and hepA ([46], see below) as well as of hetP, which has been implicated in the commitment to irreversible differentiation [47, 48]. A global study of HetR targets by chromatin immunoprecipitation identified 26 direct targets, of which only $10 \%$ are related to known heterocyst-differentiation genes [49]. Finally, a role of HetR in repression of several gene promoters in vegetative cells has been reported $[29,50,51]$.

Structurally, HetR represents a rather distinct type of transcription factor. The crystal structure of a dimer of HetR from the heterocyst-forming cyanobacterium Fischerella sp. shows a central DNA-binding region constituted by the N-terminal HTH motifs of both subunits, and new folds conforming two globular "flaps" and a "hood" over the central core, the latter formed by the two C-terminal parts [52] (Fig. 2B). However, HetR tetramers have been detected in vivo, at higher levels during heterocyst differentiation, leading to the proposal that the tetramer represents an active form of HetR [53]. This is consistent with (i) 
241 the fact that in crystals assembled by HetR in complex with long synthetic DNA targets, HetR

242 tetramers formed by interaction of the flap domains were the predominant form [54], and (ii)

243 the occurrence of tandem repeats of the HetR DNA-binding consensus sequence in several of 244 the identified HetR targets [49].

\subsection{Mechanisms of transcriptional activation by NtcA and HetR}

247 The expression of both $n t c A$ and hetR increase early during heterocyst differentiation, upon

248 combined $\mathrm{N}$ step-down, in a mutually-dependent manner enhanced by positive 249 autoregulation, with hetR induction preceding that of $n t c A$ [55]. Remarkably, induction takes 250 place in specific cells or cell clusters along the filament, marking the places of vegetative cell 251 differentiation into heterocysts ([56-58], see below). The response regulator-like factor NrrA, 252 which is directly induced by NtcA early upon $\mathrm{N}$ step-down from a canonical Class II promoter 253 [59], has been reported to bind the hetR promoter region in vitro and, hence, to mediate the 254 induction of hetR by NtcA [60].

255 Multiple genes whose products effect the morphological and biochemical 256 differentiation of heterocysts (see below), including secondary regulators, are also activated 257 upon combined $\mathrm{N}$ step-down at specific steps during differentiation [41, 61], and for some of 258 them induction could be ascribed to specific cells along the filament (see e.g. [29, 62]). In 259 contrast to $n r r A$, which is independent of HetR, in vivo activation of many other heterocyst260 differentiation genes depends on both NtcA and HetR, as they are not induced in strains 261 bearing inactivated $n t c A$ or hetR genes. Mechanistically, a remarkable feature of heterocystdifferentiation genes is that they present complex promoter sequences including several successive promoters, which may include $\sigma^{70}$ consensus-type promoters, likely directing a

264 basal level of gene expression in all the cells of the filament before $\mathrm{N}$ step-down, Class II and

265 Class I NtcA-activated promoters, and HetR-dependent promoters (see e.g. [41, 50, 63]). The 266 binding affinity of NtcA for the different NtcA-activated promoters and the response to HetR 267 are important in determining the temporal sequence of transcription activation during the 268 differentiation process that, as a result of the cell-confined increase of hetR and ntcA expression, takes place in specific cells along the filament.

HetR appears to exert a positive effect on transcription activation by several mechanisms. As mentioned above, direct binding of HetR in vitro has been reported for only a

272 few sequences upstream of heterocyst-differentiation genes [49], suggesting that the in vivo 273 requirement could be indirect in many promoters, e.g., by the requirement of high levels of 274 NtcA, attained by HetR-dependent activation of the ntcA gene, or of later secondary 
275 regulators. In the case of the proximal promoter of the devBCA operon involved in deposition 276 of the Hgl layer (see below), HetR could not bind DNA by itself but was found to increase the 277 binding of NtcA at degenerated NtcA-binding sequences, thus behaving as an NtcA-coactivator 278 [50] (Fig. 2C). On the other hand, the pipX gene, which is activated directly by NtcA at late 279 stages of heterocyst differentiation, encodes a small protein required for full diazotrophic 280 growth and full activation of further late genes [62]. The structure of a complex of the NtcA and PipX proteins from the unicellular cyanobacterium Synechococcus elongatus has been determined, leading to the suggestion that binding of PipX stabilizes the active conformation of NtcA [64]. With the Anabaena proteins, PipX has been shown to increase NtcA binding to DNA and transcription from NtcA-dependent promoters in vitro, thus representing a late NtcAcoactivator [65].

Regarding RNA polymerase sigma factors, NtcA-dependent transcription has been achieved in vitro with the Anabaena RNA polymerase holoenzyme including the principal group $1 \sigma^{70}$-family factor SigA [43]. In Anabaena, the sigA gene is transcribed from one major, proximal promoter that was first described to display constant activity [66] and later to be repressed by NtcA after $\mathrm{N}$ step-down [67]. Additionally, several promoters induced upon removal of combined nitrogen contribute to expression of sigA. This array of promoters produces increased transcription of sigA in the differentiating cells, which is consistent with a bulk of NtcA-dependent transcription during differentiation. Further, Anabaena has multiple $\sigma^{70}$-family factors of groups 2 and 3 [68]. Although inactivation of none of them abolishes heterocyst differentiation or diazotrophic growth, some of the single and double mutants that 296 have been isolated are affected in these processes [69]. Also, the sigC (group 2), sigE (group 2) 297 and sigG (group 3) genes are responsive to $\mathrm{N}$ step-down, with successive increases of 298 expression in the cells that are differentiating into heterocysts [70]. SigE is upregulated late 299 during differentiation, and both NrrA [71] and NtcA [72] directly bind to sequences upstream 300 of sigE. SigE is required for normal cellular differentiation and for expression of several 301 heterocyst-specific genes including nifH (encoding a nitrogenase subunit), $f d x H$ (encoding a 302 putative electron donor to nitrogenase [73]), $h g / E_{2}$ (encoding a heterocyst-specific glycolipid 303 biosynthesis protein [72]), and the $x f p$ operon involved in glycolysis [71]. Thus, in spite of considerable redundancy, a succession of specific $\sigma^{70}$-family factors appears to cooperate with SigA during heterocyst differentiation.

306 Finally, HetR is a target of phosphorylation in vitro and phosphorylation interferes with 307 the formation of HetR tetramers and HetR binding to DNA [53]. Consistently, overexpression in 308 Anabaena of a heterocyst-specific kinase, PknE, blocks heterocyst differentiation in a process 
309 that appears to involve inactivation of HetR [74]. The pknE gene is induced late during 310 differentiation [61] with a direct participation of HetR [74] and NtcA [38], the latter using a 311 putative Class II promoter. These independent, in vitro and in vivo observations strongly 312 suggest that phosphorylation of HetR is a physiological process, leading to the proposal that 313 phosphorylation represents a mechanism of HetR inactivation at late stages of heterocyst 314 differentiation, when a direct action of HetR would be no longer required $[53,74]$.

\section{Regulation of gene expression in the course of heterocyst} differentiation

The expression of genes involved in heterocyst differentiation and function is generally dependent on NtcA and HetR. Although regulation by these transcription factors may in some cases be indirect, evidence for direct regulation, especially by NtcA, is also available for many genes. Additionally, a number of other regulators, some of them transcription factors, have been shown to be involved in the expression of genes at specific stages of heterocyst differentiation.

Key steps in the morphological and metabolic differentiation of heterocysts are the deposition of the Hep and $\mathrm{Hgl}$ layers. During differentiation, the Hep layer is deposited before the $\mathrm{Hgl}$ layer, allowing the latter to lie beneath the former.

\subsubsection{Hep layer}

333 In the chromosome of Anabaena, numerous genes involved in Hep layer formation are 334 clustered in a "gene expression island", which covers ORFs alr2825 to alr2841 [75], and are 335 induced under nitrogen deprivation [76]. Because they are tightly packed together, the genes 336 alr2825 to alr2831 might constitute an operon, as might be the case for the genes alr2835 337 (hepA) to alr2841 as well [61]. In spite of the presence of numerous NtcA binding sites in this 338 region [38], direct NtcA-activated expression has not been reported. On the other hand, 339 induction in response to nitrogen deprivation of the hepA gene within this cluster requires 340 HetR [56], which binds to a DNA fragment from the hepA promoter [46]. Direct regulation of 341 hepA by HetR establishes a link between formation of the Hep layer and the developmental 342 cascade of gene regulation that operates heterocyst differentiation (Fig. 3). 
Expression of hepA is additionally dependent on HepK, a protein-histidine kinase of a

344 two-component regulatory system that shows homology to bacterial proteins involved in 345 acclimation to changing $\mathrm{O}_{2}$ conditions [77]. Interestingly, a normal oxic atmosphere is required 346 for differentiation of mature heterocysts [78], but it remains to be determined whether HepK 347 actually mediates a response to $\mathrm{O}_{2}$. A cognate response regulator of HepK is DevR [79], which 348 can be phosphorylated but lacks a C-terminal effector domain (RR* in Fig. 3). This suggests that 349 HepK/DevR participate in a phosphorelay transduction pathway that includes further protein 350 components, in particular a possible DNA binding protein [80].

351 Three additional putative regulatory genes that are required for production of the Hep 352 layer are hepN (alr0117) that encodes a histidine kinase that lacks a sensor domain (HK* in Fig. 353 3) [81, 82], hepS (all2760) that encodes a putatively membrane-anchored Ser-Thr kinase [82], 354 and henR (alr1086) that encodes a response regulator containing a CheY-like receiver domain 355 and a PPM-type (magnesium or manganese-dependent protein phosphatase that 356 dephosphorylates Ser and Thr residues) phosphatase domain [82]. The effect of inactivation of 357 some of these genes on global gene expression in Anabaena -analyzed with oligonucleotide 358 microarrays- has suggested that HepS and HenR belong to the same regulatory system, and 359 that HepN is part of the HepK/DevR regulatory pathway as well as of another undetermined 360 pathway [83]. To which environmental cues the HepS kinase and the HenR phosphatase respond is unknown, although expression of hepS is activated under nitrogen deprivation [61]. In summary, genes involved in formation of the Hep layer are subjected to regulation within the cascade of gene expression that operates during heterocyst differentiation promoted at least by HetR, but also to pathway-specific regulation involving two-component regulatory system(s) and protein kinases/phosphatases. A main goal of future research should be to find out whether any of these pathway-specific regulators responds to oxygen, and a point of general interest is whether any of them are subjected to direct NtcA/HetR-dependent regulation.

\subsubsection{Hgl layer} For a detailed discussion of the heterocyst envelope $\mathrm{Hgl}$ layer, the excellent review of Awai et al [84] is recommended. As is the case for the Hep layer, numerous genes involved in the

373 formation of the $\mathrm{Hgl}$ layer are clustered in the chromosome of Anabaena (ORFs all5341 to all5359), including genes involved in the biosynthesis of the glycolipids and genes involved in their deposition outside of the outer membrane $[85,86]$. Further genes necessary for the formation of the $\mathrm{Hgl}$ layer are located outside this cluster, and these include the $\operatorname{dev} B C A$ operon encoding and $A B C$ exporter that, together with a TolC-like protein ( $\mathrm{HgdD})$, constitutes a 
378 Type I secretion system involved in the export of glycolipids outside of the outer membrane in

379 the differentiating heterocyst [87]. Along the $\mathrm{Hgl}$ cluster, NtcA binds to several sites, including

380 sites upstream of genes all5341 (hg/T) and asr5350 as well as in the region between all5347

381 and all5348, which could constitute activator sites [38]. On the other hand, as described

382 above, the promoter of the $\operatorname{devBCA}$ operon is a well-characterized, complex NtcA-dependent

383 promoter $[50,88,89]$. It contains one canonical Class II NtcA-activated promoter and one noncanonical promoter that appears to be activated by NtcA assisted by HetR [50].

Inactivation of the hepS and henR genes involved in formation of the Hep layer also down-regulates expression of genes involved in the formation of the $\mathrm{Hgl}$ layer such as $h g \mid E_{A}$ (alr5351) [83]. On the other hand, DevH is a CRP-family transcriptional regulator whose expression is increased under nitrogen deprivation in an NtcA- and HetR-dependent mode [90]. Inactivation of devH affects specifically the expression of Hgl-biosynthesis genes such as $h g / E_{A}$ and the production of $\mathrm{Hgl}$ [91]. Whether HepS/HenR and DevH act in concert in the regulation of expression of $\mathrm{hgl}$ genes is unknown (discussed in [83]). Anabaena has two heterocyst-specific glycolipids. Production of the minor one appears to be dependent also on two Ser/Thr kinases, Pkn44 (All1625) and Pkn30 (All3691) [92], and production of the major one appears to be dependent on a specific protein phosphatase, PrpJ1 (All1731), that also affects expression of $h g / E_{A}$ [93]. The possibility that PKn44/Pkn30 and PrpJ1 belong to two different regulatory branches for production of the minor and major Hgls, respectively, acting downstream of DevH has been discussed [92].

In summary, expression of genes for the formation of the $\mathrm{Hgl}$ layer involves transcription factors including the well-known NtcA and HetR proteins discussed above and DevH. In the case of DevH, the mechanism of dependence on NtcA and HetR and the direct DNA targets remain to be elucidated. Additionally, protein kinases and phosphatases affect the formation of the $\mathrm{Hgl}$ layer as a whole and specifically the major and minor glycolipids of that layer. The environmental cues to which such kinases and phosphatases respond and how they affect glycolipid production remain to be determined (e.g., they could affect transcription factors or directly the activity of biosynthetic enzymes).

\subsection{Oxygen-consuming enzymes and protection against ROS}

Oxygen that enters the heterocyst is reduced by at least two types of enzymatic processes: respiration [4] and reduction by flavodiiron proteins [94]. Additionally, a ruberythrin, RbrA,

410 protects against oxidative stress in the heterocyst [95]. In Anabaena, two terminal respiratory 411 oxidases, Cox2 and Cox3, substitute in the heterocyst for the terminal respiratory oxidase, 
412 Cox1, expressed in vegetative cells [21]. Cox2 is an $a a_{3}$-type cytochrome $c$ oxidase encoded by

413 the coxB2-coxA2-coxC2 operon and Cox3 appears to be an heme-copper quinol oxidase that is

414 encoded by the alr2729-alr2730-coxB3-coxA3-coxC3 operon. The contribution of Cox3 to

415 protection of nitrogenase appears to be more important than that of Cox2 [21, 96]. The

416 expression of both operons is strictly dependent on NtcA and HetR. The cox3 promoter region

417 has been characterized in detail and found to contain both Class I and Class II NtcA-dependent

418 promoters in which NtcA appears to work assisted by PipX [65].

419 Flavodiiron proteins directly reduce $\mathrm{O}_{2}$ to water without the production of deleterious

420 reactive oxygen species (ROS) [97]. In Anabaena, two flavodiiron proteins, Flv1B and Flv3B, are

421 specifically expressed in the heterocysts [94], being Flv3B especially relevant for diazotrophic

422 performance [22]. These flavodiiron proteins are the products of two contiguous genes,

423 all0178 (Flv3B) and all0177 (Flv1B), which may constitute an operon expressed from an NtcA-

424 dependent promoter [38].

425 Interestingly, scavenging of $\mathrm{O}_{2}$ by terminal respiratory oxidases and flavodiiron

426 proteins appears not to be redundant [38]. Whereas the terminal respiratory oxidases likely

427 remove $\mathrm{O}_{2}$ in the heterocyst poles, since respiratory activity is located at the honeycomb

428 membrabes [98], the heterocyst falvodiiron proteins are cytoplasmic [94]. Photosystem I-

429 generated reductants can also reduce $\mathrm{O}_{2}$, but in this case producing ROS. In Anabaena, the

430 rubrerythrin RbrA is a heterocyst-specific peroxidase that transfers electrons from NADPH to

$431 \mathrm{H}_{2} \mathrm{O}_{2}$ with the participation of ferredoxin-NADP ${ }^{+}$oxidoreductase [95]. The rbrA gene is

432 expressed from two promoters one of which directs expression in the heterocysts, is 433 dependent on HetR and binds HetR in vitro [95].

434

4.3. Particular heterocyst metabolism genes

436 The metabolism of the heterocyst is focused on the fixation of $\mathrm{N}_{2}$ and the assimilation of the $\mathrm{N}$

437 fixed in that reaction. We shall address now the transcriptional regulation of nif genes and of 438 nitrogen assimilation genes such as those encoding glutamine synthetase and cyanophycin 439 metabolism enzymes, as well as other relevant genes.

440

\subsection{1. nif gene expression}

442 In diazotrophic bacteria, the nitrogenase structural genes, nifH-nifD-nifK, are generally

443 clustered together with other nitrogen fixation genes -including, e.g., genes encoding 444 nitrogenase electron donors such as specific ferredoxins- and nitrogenase maturation genes 445 such as FeMo-cofactor biosynthesis genes (99). The Anabaena genome bears a large nif gene 
cluster including nifB-fdxN-nifS-nifU-nifH-nifD-nifK-nifE-nifN-nifX and a few other genes

447 downstream. Notably, $f d x N$ and nifD are interrupted by long DNA elements that are excised 448 during heterocyst differentiation [100]. After excision, the nifHDK operon is mainly expressed 449 from a promoter located upstream from nifB [101], although the large mRNA produced is 450 subjected to processing so that nifHDK, nifHD and nifH transcripts are produced (see e.g. [96]). 451 In Anabaena and other diazotrophic cyanobacteria, including non-heterocystous strains, the nifB promoter is activated by CnfR [102], previously known as PatB [103]. The CnfR protein has $\mathrm{N}$-terminal sequences for binding two 4Fe-4S clusters, resembling bacterial-type ferredoxins, and a C-terminal HTH motif for binding to DNA $[103,104]$. It is thought that CnfR can activate nif gene expression in response to a low-oxygen tension [104, 105], and putative CnfR-binding sites have been characterized in the promoter region of nifB $[105,106]$.

In Anabaena, expression of $c n f R$ (patB) is induced in response to nitrogen deprivation $[61,103]$, exclusively in heterocysts [107]. Based on the presence of consensus NtcA-binding sites upstream of $c n f R$, it can be suggested that this gene is subjected to NtcA-dependent expression in both heterocyst-forming and $\mathrm{N}_{2}$-fixing, non-heterocystous cyanobacteria [38, 105]. Anabaena variabilis harbors two nif gene clusters, nif1 that is expressed in the heterocysts and nif2 that is expressed in the vegetative cells under micro-oxic conditions (see e.g. [106]), and expression of the nif2 cluster regulatory gene $c n f R 2$ has been shown to require NtcA [104]. Therefore, expression of $c n f R 2$ is activated when combined nitrogen is scarce, but the Fe-S clusters may be formed only when the oxygen tension is low resulting in a protein that can promote expression of the nifB operon only under micro-oxic conditions [104, 105].

\subsubsection{Expression of petH}

The petH gene encodes ferredoxin-NADP ${ }^{+}$oxidoreductase that is expressed at much higher levels in heterocysts than in vegetative cells [108], consistent with a very relevant role of this enzyme in the distribution of electrons in the heterocyst [19]. In heterocysts, petH is expressed from an NtcA-dependent promoter to which NtcA directly binds [109]. No good NtcA-binding site is however found in this promoter, suggesting the involvement of an NtcA coactivator such as PipX.

\subsubsection{Expression of $g \ln A$}

477 Glutamine synthetase, which incorporates into glutamate the ammonium produced in the $\mathrm{N}_{2}$ 478 fixation reaction to synthesize glutamine, is present at higher levels in the heterocysts than in 479 vegetative cells [110]. The glnA gene encoding glutamine synthetase is expressed at higher 
levels in the absence than in the presence of combined nitrogen, being transcribed from a complex promoter region [111]. The promoter most proximal to the gene is a Class II NtcAdependent promoter that is used during growth with nitrate and under deprivation of combined $\mathrm{N}[34,35]$. This is the $g \ln A$ promoter that is used in the heterocysts, and its dependence on NtcA has been corroborated by mutation of its NtcA-binding site [112].

\subsubsection{Cyanophycin metabolism genes}

As mentioned earlier, the dynamic $\mathrm{N}$ reservoir cyanophycin is accumulated conspicuously at the heterocyst poles. In Anabaena, the genes encoding the main cyanophycin synthetase (all3879, cphA1) and cyanophycinase (all3880, cphB1) are clustered together. These genes are expressed as an operon (cphB1-cphA1) from a complex promoter region localized upstream of $c p h B 1$, and $c p h A 1$ is also transcribed monocistronically from a complex promoter present in the intergenic region. In these regions, NtcA-dependent promoters comprising high- and lowaffinity NtcA-binding sites are found which are active in heterocysts [113]. The gene all3922, encoding isoaspartyl dipeptidase that hydrolyzes the dipeptide $\beta$-aspartyl arginine, is induced under nitrogen deprivation [61] and is expressed preferentially in vegetative cells [28], consistent with the transfer of the dipeptide from the heterocysts to the vegetative cells.

\subsubsection{Expression of RuBisCO}

As mentioned earlier, the RuBisCO enzyme is not active in the heterocysts thus avoiding the investment of energy and reductant in the fixation of $\mathrm{CO}_{2}$, a process confined to the vegetative cells. Lack of RuBisCO in the heterocysts results from repression of gene expression [114], and binding of NtcA to a DNA site overlapping the translation start of the $r b c L X S$ operon encoding RuBisCO appears to represent a mechanism of repression $[38,115]$. This mechanism of cellspecific repression of RuBisCO stresses the relevant role of NtcA in regulation of gene expression, not only by induction but also by repression, in the mature heterocyst.

\section{Heterocyst patterning}

Heterocyst distribution is not random in the cyanobacterial filaments, but instead it follows a relatively fixed pattern. In most strains of the order Nostocales, heterocysts are separated by

511 ca. 10 to 15 vegetative cells along the filament. Importantly, this pattern is established early 512 upon $\mathrm{N}$ step-down, implying that products of $\mathrm{N}_{2}$ fixation are not required for generation of at 513 least the initial pattern. 
516 Several theoretical models have been put forward to try a mathematical description of the

517 generation of the heterocyst distribution pattern, and most of those models are based on the 518 operation of an activator and an inhibitor of differentiation with different intercellular 519 diffusivities (revised in [116]). The HetR transcription factor has been considered as the 520 activator in these models. As mentioned above, basal expression of hetR takes place in the 521 filament even in the presence of ammonium, and expression fluctuations are coupled in 2-4 522 nearby cells influenced by positive autoregulation ([117]; J. Stavans, personal communication). 523 Moreover, this pattern persists during the initial stages of development upon $\mathrm{N}$ step-down 524 [117], which could explain the classical observation that differentiation is first observed in 525 small clusters of cells that are later resolved to single heterocysts [8]. Thus, coupled 526 fluctuations of hetR expression after $\mathrm{N}$ step-down would build-up upon the basic pattern 527 already latent under $\mathrm{N}$-replete conditions. At intermediate stages of differentiation, an 528 increase in autocorrelation functions of hetR expression is observed [117], which would result 529 from increased hetR autoregulation in response to $n t c A$ (and $n r r A$ ) induction.

532 The pats gene is induced early in specific cells, depending on HetR [46], and its overexpression 533 abolishes heterocyst differentiation, whereas its inactivation leads to the formation of 534 heterocysts in groups (the so called $\mathrm{MCH}$, multiple contiguous heterocysts phenotype). Hence, 535 it was suggested that a patS gene product effects a lateral inhibition of differentiation [118]. 536 The primary product of the patS gene is a 17-amino acid peptide that is processed to render a 537 smaller active peptide including the C-terminal part of the primary gene product $[118,119]$, 538 likely consisting of the C-terminal seven residues $[119,120]$. Nonetheless, a peptide consisting 539 of only the five C-terminal amino acids of PatS can also suppress heterocyst differentiation 540 when added to Anabaena cultures [118]. The active PatS peptide (which we will denote 541 hereafter PatS*) is transferred to the neighboring cells to establish a concentration gradient 542 with highest levels in the cells adjacent to the producing cell, in which the concentration 543 remains negligible, and decreasing thereon, thus behaving as a morphogen [119]. The $\mathrm{N}$ 544 terminal half of the pats primary product is important for processing of the peptide and for 545 conferring immunity against the inhibitory activity in the producing cell, which would involve 546 peptide excretion [119]. 
The hetC gene encodes an ABC-type exporter that includes a putative peptidase

548 domain required for heterocyst differentiation $[121,122]$. hetC is expressed from a complex 549 promoter region that includes a canonical NtcA-dependent promoter and a HetR- and NtcA550 dependent promoter, similar to the promoter region of the $\operatorname{devBAC}$ operon $[43,89]$. HetC 551 localizes mostly to the heterocyst poles [122], and the possibility of its involvement in export 552 of PatS* from the differentiating heterocysts has been considered $[122,123]$, as has also been 553 considered the participation of the septal junction protein SepJ in the intercellular transfer of 554 PatS* between vegetative cells [124]. Regarding the inhibitory activity of the morphogen, 555 PatS* has been shown to interact with $\operatorname{HetR}[125,126]$, to influence the turnover of HetR 556 [127], and to inhibit HetR tetramer accumulation [53] and HetR binding to DNA [46]. All these observations are fully consistent with the reported isolation of a suppressor mutant of patS overexpression, which bore a mutation in the hetR gene [128]. Thus, at least one component of the inhibition of heterocyst differentiation by PatS* is the inhibition of HetR activity. Figure

5604 presents a hypothetical model in which (i) HetC participates in processing of PatS and transfer of PatS* from the (pro)heterocyst to its neighboring vegetative cell, and (ii) SepJ participates in spreading of PatS* between vegetative cells along the filament. How PatS* is prevented from moving back to the (pro)heterocyst through SepJ-related conduits is unknown, but may be related to the distinct architecture of the septal junctions in vegetative cellheterocyst septa described above.

Besides being dependent on hetR auto-regulation, the spatial correlation of hetR expression fluctuations along the filament, both in the presence of ammonium and early after $\mathrm{N}$ step-down, is influenced by expression of patS and intercellular communication dependent on SepJ [117]. This implies the existence of a basal expression of patS in the presence of ammonium, consistent with the reported detection of patS transcription in the presence of combined nitrogen [8]. Thus, fluctuations in the expression of hetR encoding a positive regulator of differentiation, HetR positive autoregulation, lateral inhibition by PatS (whose synthesis depends on HetR), and cell-to-cell communication are fundamental components of the developmental process.

\subsection{Other proteins influencing pattern formation} Finally, other protein factors -including HetL, HetN, PatA, PatL and PatN- have been described

578 to influence the spatial pattern of heterocyst distribution. The hetN gene influences the 579 pattern of heterocysts especially at advanced stages of differentiation $[129,130]$. This effect 580 likely involves an internal hexapeptide sequence identical to the C-terminal sequence of PatS $581[130,131]$. Indeed, at late, but not at early times after $\mathrm{N}$ step-down, expression of het $N$ has 
582 been shown to influence the coupling of hetR expression fluctuations through the filament

583 [117]. At times when heterocyst differentiation is already completed, the FraC/FraD proteins

584 involved in intercellular molecular exchange impact hetR expression correlations in 585 neighboring cells in a manner similar to SepJ [117]. This effect of FraC/FraD could involve 586 transfer of a HetN-derived product or other regulators or $\mathrm{N}_{2}$ fixation-derived metabolites.

Whereas inactivation of patN results in an increased heterocyst frequency $[132,133]$, inactivation of patA [134] or patL [135] results in the preferential production of terminal heterocysts in the filaments (implying a decreased heterocyst frequency). On the other hand, overexpression of hetL increases heterocyst frequency [136]. PatL and HetL are pentapeptide repeat proteins of unknown function, PatA and PatL have been shown to interact with each other [135], and PatN has been shown to influence the expression of patA [132]. Significantly,

593 the patA gene is transcribed in differentiating heterocysts from two NtcA-activated promoters

594 [137]. PatA is a response regulator that lacks a DNA binding domain and counteracts PatS and HetN inhibition of heterocyst differentiation [138].

\section{Concluding remarks}

598

Heterocyst differentiation from a vegetative cell involves changes in expression of several 600 hundred genes [139], including repression and induction (thoroughly reviewed by Xu et al. 601 [140]). Several transcription factors effecting this regulation have been identified mainly in the 602 model organism Anabaena (Table 1). NtcA and HetR are absolutely needed for heterocyst 603 differentiation, whereas other transcription factors participate in specific steps of the 604 differentiation process. NtcA and HetR are however not equivalent. Whereas NtcA is a global 605 transcription factor that activates numerous gene promoters at different steps of 606 differentiation, and represses some promoters as well, HetR has been shown to bind to few 607 DNA sequences possibly activating transcription. Additionally, the strict requirement for HetR 608 may rely on (i) its effect on localized induction of $n t c A$ in the developing heterocyst and (ii) a 609 role as a coactivator of NtcA at specific promoters. An additional coactivator of NtcA is PipX, 610 which being expressed late in heterocyst differentiation supports NtcA-dependent activation 611 of late genes, including some that are expressed in mature heterocysts. In the mature 612 heterocyst, the $r b c L$ operon promoter is directly repressed by NtcA, and a highly-expressed 613 gene such as $g \ln A$ is transcribed from a canonical Class II NtcA-dependent promoter, raising 614 the possibility that expression in the mature heterocyst no longer requires differentiation615 specific transcription factors. This is consistent with an inactivation of HetR by phosphorylation 
616 as discussed above. Finally, in the mature heterocyst, expression of the nif genes requires a

617 specific transcription factor $(\mathrm{CnfR})$ that may link expression to the micro-oxic conditions 618 prevailing in the differentiated cell.

619

620 Acknowledgements

621

622 Work in the authors' laboratory is currently funded by grants number BFU2014-56757-P and 623 BFU2017-88202-P (E.F.) and BFU2016-77097-P (AH) from Agencia Estatal de Investigación, 624 Spain, co-financed by the European Regional Development Fund.

625

626 
[1] Tomitani A, Knoll AH, Cavanaugh CM, Ohno T, The evolutionary diversification of cyanobacteria: molecular-phylogenetic and paleontological perspectives., Proc Natl Acad Sci USA 103 (2006) 54427.

[2] Rippka R, Deruelles J, Waterbury JB, Herdman M, Stanier RY, Generic assignments, strain histories and properties of pure cultures of cyanobacteria, J Gen Microbiol 111 (1979) 1-61

634

635

[3] Gallon JR, The oxygen sensitivity of nitrogenase: a problem for biochemists and micro-organisms, TIBS 6 (1981) 19-23

[4] Fay P, Oxygen relations of nitrogen fixation in cyanobacteria, Microbiol Rev 56 (1992) 340-73.

637

[5] Flores E, Herrero A, Compartmentalized function through cell differentiation in filamentous cyanobacteria, Nat Rev Microbiol 8 (2010) 39-50.

639

640

[6] Maldener I, Summers ML, Sukenik A, Cellular differentiation in filamentous cyanobacteria, in: Flores E, Herrero A (Eds.) The Cell Biology of Cyanobacteria, Caister Academic Press, Norfolk, UK (2014) pp. 263-291.

642

643

[7] Bradley S, Carr NG, Heterocyst and nitrogenase development in Anabaena cylindrica, J Gen Microbiol 96 (1976) 175-84.

644

[8] Yoon HS, Golden JW, PatS and products of nitrogen fixation control heterocyst pattern, J Bacteriol 183 (2001) 2605-13.

646

647

648

649

[9] Wilk L, Strauss M, Rudolf M, Nicolaisen K, Flores E, Kühlbrandt W, Schleiff E, Outer membrane continuity and septosome formation between vegetative cells in the filaments of Anabaena sp. PCC 7120, Cell Microbiol 13 (2011) 1744-54.

[10] Mariscal V, Herrero A, Flores E, Continuous periplasm in a filamentous, heterocyst-forming cyanobacterium, Mol Microbiol 65 (2007) 1139-45.

651

652

[11] Flores E, Herrero A, Forchhammer K, Maldener I, Septal junctions in filamentous heterocyst-forming cyanobacteria, Trends Microbiol 24 (2016) 79-82.

653

[12] Lehner J, Berendt S, Dörsam B, Pérez R, Forchhammer K, Maldener I, Prokaryotic multicellularity: a nanopore array for bacterial cell communication, FASEB J 27 (2013) 2293-300.

655

656

[13] Nürnberg DJ, Mariscal V, Bornikoel J, Nieves-Morión M, Krauß N, Herrero A, Maldener I, Flores E, Mullineaux $\mathrm{CW}$, Intercellular diffusion of a fluorescent sucrose analog via the septal junctions in a filamentous cyanobacterium, mBio 6 (2015) e02109.

[14] Bornikoel J, Carrión A, Fan Q, Flores E, Forchhammer K, Mariscal V, Mullineaux CW, Perez R, Silber $\mathrm{N}$, Wolk CP, Maldener I, Role of two cell wall amidases in septal junction and nanopore formation in the multicellular cyanobacterium Anabaena sp. PCC 7120, Front Cell Infect Microbiol 7 (2017) 386.

[15] Flores E, Pernil R, Muro-Pastor AM, Mariscal V, Maldener I, Lechno-Yossef S, Fan Q, Wolk CP, Herrero A, Septum-localized protein required for filament integrity and diazotrophy in the heterocyst-forming cyanobacterium Anabaena sp. strain PCC 7120, J Bacteriol 189 (2007) 3884-90.

[16] Merino-Puerto V, Mariscal V, Mullineaux CW, Herrero A, Flores E, Fra proteins influencing filament integrity, diazotrophy and localization of septal protein SepJ in the heterocyst-forming cyanobacterium Anabaena sp., Mol Microbiol 75 (2010) 1159-70.

[17] Merino-Puerto V, Schwarz H, Maldener I, Mariscal V, Mullineaux CW, Herrero A, Flores E, FraC/FraD-dependent intercellular molecular exchange in the filaments of a heterocyst-forming cyanobacterium, Anabaena sp., Mol Microbiol 82 (2011) 87-98.

[18] Ramos-León F, Mariscal V, Battchikova N, Aro EM, Flores E, Septal protein SepJ from the heterocystforming cyanobacterium Anabaena forms multimers and interacts with peptidoglycan, FEBS Open Bio 7 (2017) 1515-1526.

[19] Magnuson A, Cardona T, Thylakoid membrane function in heterocysts. Biochim Biophys Acta 1857 (2016) 309-19. 
[20] Walsby AE, Cyanobacterial heterocysts: terminal pores proposed as sites of gas exchange, Trends Microbiol 15 (2007) 340-9.

678

679

680

681

682

683

684

685

686

687

688

689

690

691

692

693

694

695

696

697

698

699

700

701

702

703

704

705

706

707

708

709

710

711

712

713

714

715

716

717

718

719

720

721

722

723

724

[21] Valladares A, Herrero A, Pils D, Schmetterer G, Flores E, Cytochrome $c$ oxidase genes required for nitrogenase activity and diazotrophic growth in Anabaena sp. PCC 7120, Mol Microbiol 47 (2003) 1239-49.

[22] Ermakova M, Battchikova N, Richaud P, Leino H, Kosourov S, Isojärvi J, Peltier G, Flores E, Cournac L, Allahverdiyeva $Y$, Aro EM, Heterocyst-specific flavodiiron protein Flv3B enables oxic diazotrophic growth of the filamentous cyanobacterium Anabaena sp. PCC 7120, Proc Natl Acad Sci USA 111 (2014) 11205-10.

[23] Wolk CP, Thomas J, Shaffer PW, Austin SM, Galonsky A, Pathway of nitrogen metabolism after fixation of ${ }^{13} \mathrm{~N}$-labeled nitrogen gas by the cyanobacterium, Anabaena cylindrica, J Biol Chem 251 (1976) 5027-34.

[24] Thomas J, Meeks JC, Wolk CP, Shaffer PW, Austin SM, Formation of glutamine from $\left[{ }^{13} \mathrm{~N}\right]$ ammonia, $\left[{ }^{13} \mathrm{~N}\right]$ dinitrogen, and $\left[{ }^{14} \mathrm{C}\right]$ glutamate by heterocysts isolated from Anabaena cylindrica, J Bacteriol 129 (1977) 1545-55.

[25] Martín-Figueroa E, Navarro F, Florencio FJ, The GS-GOGAT pathway is not operative in the heterocysts. Cloning and expression of $\mathrm{glsF}$ gene from the cyanobacterium Anabaena sp. PCC 7120, FEBS Lett 476 (2000) 282-6.

[26] Sherman DM, Tucker D, Sherman LA, Heterocyst development and localization of cyanophycin in $\mathrm{N}_{2}$-fixing cultures of Anabaena sp. PCC 7120 (Cyanobacteria), J Phycol 36 (2000) 932-941.

[27] Herrero A, Burnat $M$, Cyanophycin, a cellular nitrogen reserve material, in: Flores E, Herrero A (Eds.) The Cell Biology of Cyanobacteria, Caister Academic Press, Norfolk, UK (2014) pp. 211-219.

[28] Burnat M, Herrero A, Flores E, Compartmentalized cyanophycin metabolism in the diazotrophic filaments of a heterocyst-forming cyanobacterium, Proc Natl Acad Sci USA 111 (2014) 3823-8.

[29] López-Igual R, Flores E, Herrero A, Inactivation of a heterocyst-specific invertase indicates a principal role of sucrose catabolism in heterocysts of Anabaena sp., J Bacteriol 192 (2010) 552633.

[30] Vargas WA, Nishi CN, Giarrocco LE, Salerno GL, Differential roles of alkaline/neutral invertases in Nostoc sp. PCC 7120: Inv-B isoform is essential for diazotrophic growth, Planta 233 (2011) 153-62.

[31] Mullineaux CW, Mariscal V, Nenninger A, Khanum H, Herrero A, Flores E, Adams DG, Mechanism of intercellular molecular exchange in heterocyst-forming cyanobacteria, EMBO J 27 (2008) 1299308.

[32] Nieves-Morión M, Mullineaux CW, Flores E, Molecular diffusion through cyanobacterial septal junctions, mBio 8 (2017) e01756-16.

[33] Omairi-Nasser A, Mariscal V, Austin JR 2nd, Haselkorn R, Requirement of Fra proteins for communication channels between cells in the filamentous nitrogen-fixing cyanobacterium Anabaena sp. PCC 7120, Proc Natl Acad Sci USA 112 (2015) E4458-64.

[34] Frías JE, Flores E, Herrero A, Requirement of the regulatory protein NtcA for the expression of nitrogen assimilation and heterocyst development genes in the cyanobacterium Anabaena sp. PCC 7120, Mol Microbiol 14 (1994) 823-32.

[35] Wei TF, Ramasubramanian TS, Golden JW, Anabaena sp. strain PCC 7120 ntcA gene required for growth on nitrate and heterocyst development, J Bacteriol 176 (1994) 4473-82.

[36] Buikema WJ, Haselkorn R, Characterization of a gene controlling heterocyst differentiation in the cyanobacterium Anabaena 7120, Genes Dev 5 (1991) 321-30.

[37] Luque I, Flores E, Herrero A, Molecular mechanism for the operation of nitrogen control in cyanobacteria, EMBO J 13 (1994) 2862-9.

[38] Picossi S, Flores E, Herrero A, ChIP analysis unravels an exceptionally wide distribution of DNA binding sites for the NtcA transcription factor in a heterocyst-forming cyanobacterium, BMC Genomics 15 (2014) 22. 
[39] Zhao MX, Jiang YL, He YX, Chen YF, Teng YB, Chen Y, Zhang CC, Zhou CZ, Structural basis for the allosteric control of the global transcription factor NtcA by the nitrogen starvation signal 2oxoglutarate, Proc Natl Acad Sci USA 107 (2010) 12487-92.

[40] Luque I, Forchhammer $\mathrm{K}$, Nitrogen assimilation and $\mathrm{C} / \mathrm{N}$ balance sensing, in: Herrero $\mathrm{A}$, Flores $\mathrm{E}$ (Eds.) The Cyanobacteria: Molecular Biology, Genomics and Evolution, Caister Academic Press, Norfolk, UK (2008) pp. 335-382.

[41] Herrero A, Picossi S, Flores E, Gene expression during heterocyst differentiation, Adv Bot Res 65 (2013) 281-329.

[42] Vázquez-Bermúdez MF, Herrero A, Flores E, 2-Oxoglutarate increases the binding affinity of the NtcA (nitrogen control) transcription factor for the Synechococcus glnA promoter, FEBS Lett 512 (2002) 71-4.

[43] Valladares A, Flores E, Herrero A, Transcription activation by NtcA and 2-oxoglutarate of three genes involved in heterocyst differentiation in the cyanobacterium Anabaena sp. strain PCC 7120, J Bacteriol 190 (2008) 6126-33.

[44] López-Igual R, Picossi S, López-Garrido J, Flores E, Herrero A, N and C control of ABC-type bicarbonate transporter $\mathrm{Cmp}$ and its LysR-type transcriptional regulator $\mathrm{CmpR}$ in a heterocystforming cyanobacterium, Anabaena sp., Environ Microbiol 14 (2012) 1035-48.

[45] Zhang JY, Chen WL, Zhang CC, hetR and patS, two genes necessary for heterocyst pattern formation, are widespread in filamentous nonheterocyst-forming cyanobacteria, Microbiology 155 (2009) 1418-26.

[46] Huang $X$, Dong $Y$, Zhao J, HetR homodimer is a DNA-binding protein required for heterocyst differentiation, and the DNA-binding activity is inhibited by PatS, Proc Natl Acad Sci USA 101 (2004) 4848-53.

[47] Higa KC, Callahan SM, Ectopic expression of hetP can partially bypass the need for hetR in heterocyst differentiation by Anabaena sp. strain PCC 7120, Mol Microbiol 77 (2010) 562-74.

[48] Videau P, Rivers OS, Hurd K, Ushijima B, Oshiro RT, Ende RJ, O'Hanlon SM, Cozy LM, The heterocyst regulatory protein HetP and its homologs modulate heterocyst commitment in Anabaena sp. strain PCC 7120, Proc Natl Acad Sci USA (2016) pii: 201610533.

[49] Flaherty BL, Johnson DB, Golden JW, Deep sequencing of HetR-bound DNA reveals novel HetR targets in Anabaena sp. strain PCC7120, BMC Microbiol 14 (2014) 255.

[50] Camargo S, Valladares A, Flores E, Herrero A, Transcription activation by NtcA in the absence of consensus NtcA-binding sites in an Anabaena heterocyst differentiation gene promoter, J Bacteriol 194 (2012) 2939-48.

[51] Videau P, Ni S, Rivers OS, Ushijima B, Feldmann EA, Cozy LM, Kennedy MA, Callahan SM, Expanding the direct HetR regulon in Anabaena sp. strain PCC 7120, J Bacteriol 196 (2014) 1113-21.

[52] Kim Y, Joachimiak G, Ye Z, Binkowski TA, Zhang R, Gornicki P, Callahan SM, Hess WR, Haselkorn R, Joachimiak $A$, Structure of transcription factor HetR required for heterocyst differentiation in cyanobacteria, Proc Natl Acad Sci USA 108 (2011) 10109-14.

[53] Valladares A, Flores E, Herrero A, The heterocyst differentiation transcriptional regulator HetR of the filamentous cyanobacterium Anabaena forms tetramers and can be regulated by phosphorylation, Mol Microbiol 99 (2016) 808-19.

[54] Kim Y, Ye Z, Joachimiak G, Videau P, Young J, Hurd K, Callahan SM, Gornicki P, Zhao J, Haselkorn R, Joachimiak A, Structures of complexes comprised of Fischerella transcription factor HetR with Anabaena DNA targets, Proc Natl Acad Sci USA 110 (2013) E1716-23.

[55] Muro-Pastor AM, Valladares A, Flores E, Herrero A, Mutual dependence of the expression of the cell differentiation regulatory protein HetR and the global nitrogen regulator NtcA during heterocyst development. Mol Microbiol 44 (2002) 1377-85.

[56] Black TA, Cai Y, Wolk CP, Spatial expression and autoregulation of het $R$, a gene involved in the control of heterocyst development in Anabaena, Mol Microbiol 9 (1993) 77-84. Erratum in: Mol Microbiol 10 (1993) 1153. 
[57] Olmedo-Verd E, Muro-Pastor AM, Flores E, Herrero A, Localized induction of the ntcA regulatory gene in developing heterocysts of Anabaena sp. strain PCC 7120, J Bacteriol 188 (2006) 6694-9.

777

[58] Rajagopalan R, Callahan SM, Temporal and spatial regulation of the four transcription start sites of hetR from Anabaena sp. strain PCC 7120, J Bacteriol 192 (2010) 1088-96.

[59] Muro-Pastor AM, Olmedo-Verd E, Flores E, All4312, an NtcA-regulated two-component response regulator in Anabaena sp. strain PCC 7120, FEMS Microbiol Lett 256 (2006) 171-7.

[60] Ehira S, Ohmori M, NrrA_directly regulates expression of hetR during heterocyst differentiation in the cyanobacterium Anabaena sp. strain PCC 7120, J Bacteriol 188 (2006) 8520-5.

[61] Flaherty BL, Van Nieuwerburgh F, Head SR, Golden JW, Directional RNA deep sequencing sheds new light on the transcriptional response of Anabaena sp. strain PCC 7120 to combined-nitrogen deprivation, BMC Genomics 12 (2011) 332.

[62] Valladares A, Rodríguez V, Camargo S, Martínez-Noël GM, Herrero A, Luque I, Specific role of the cyanobacterial PipX factor in the heterocysts of Anabaena sp. strain PCC 7120, J Bacteriol 193 (2011) 1172-82.

[63] Mitschke J, Vioque A, Haas F, Hess WR, Muro-Pastor AM, Dynamics of transcriptional start site selection during nitrogen stress-induced cell differentiation in Anabaena sp. PCC7120, Proc Natl Acad Sci USA 108 (2011) 20130-5.

[64] Llácer JL, Espinosa J, Castells MA, Contreras A, Forchhammer K, Rubio V, Structural basis for the regulation of NtcA-dependent transcription by proteins PipX and PII, Proc Natl Acad Sci USA 107 (2010) 15397-402.

[65] Camargo S, Valladares A, Forchhammer K, Herrero A, Effects of PipX on NtcA-dependent promoters and characterization of the cox3 promoter region in the heterocyst-forming cyanobacterium Anabaena sp. PCC 7120, FEBS Lett 588 (2014) 1787-94.

[66] Brahamsha B, Haselkorn R, Isolation and characterization of the gene encoding the principal sigma factor of the vegetative cell RNA polymerase from the cyanobacterium Anabaena sp. strain PCC 7120, J Bacteriol 173 (1991) 2442-50.

[67] Muro-Pastor AM, Brenes-Álvarez M, Vioque A, A combinatorial strategy of alternative promoter use during differentiation of a heterocystous cyanobacterium, Environ Microbiol Rep 9 (2017) 449458.

[68] Imamura S, Asayama M, Sigma factors for cyanobacterial transcription, Gene Regul Syst Bio 3 (2009) 65-87.

[69] Khudyakov IY, Golden JW, Identification and inactivation of three group 2 sigma factor genes in Anabaena sp. strain PCC 7120, J Bacteriol 183 (2001) 6667-75.

[70] Aldea MR, Mella-Herrera RA, Golden JW, Sigma factor genes sigC, sigE, and sigG are upregulated in heterocysts of the cyanobacterium Anabaena sp. strain PCC 7120, J Bacteriol 189 (2007) 8392-6.

[71] Ehira S, Ohmori M, NrrA, a nitrogen-regulated response regulator protein, controls glycogen catabolism in the nitrogen-fixing cyanobacterium Anabaena sp. strain PCC 7120, J Biol Chem 286 (2011) 38109-14.

[72] Mella-Herrera RA, Neunuebel MR, Kumar K, Saha SK, Golden JW, The sigE gene is required for normal expression of heterocyst-specific genes in Anabaena sp. strain PCC 7120, J Bacteriol 193 (2011) 1823-32.

[73] Schrautemeier B, Neveling U, Schmitz S, Distinct and differently regulated Mo-dependent nitrogenfixing systems evolved for heterocysts and vegetative cells of Anabaena variabilis ATCC 29413: characterization of the $f d x H 1 / 2$ gene regions as part of the nif1/2 gene clusters, Mol Microbiol 18 (1995) 357-69.

[74] Saha SK, Golden JW, Overexpression of pknE blocks heterocyst development in Anabaena sp. strain PCC 7120, J Bacteriol 193 (2011) 2619-29. 
[75] Huang G, Fan Q, Lechno-Yossef S, Wojciuch E, Wolk CP, Kaneko T, Tabata S, Clustered genes required for the synthesis of heterocyst envelope polysaccharide in Anabaena sp. strain PCC 7120, J Bacteriol 187 (2005) 1114-23.

[76] Ehira S, Ohmori M, Sato N, Genome-wide expression analysis of the responses to nitrogen deprivation in the heterocyst-forming cyanobacterium Anabaena sp. strain PCC 7120, DNA Res 10 (2003) 97-113.

[77] Zhu J, Kong R, Wolk CP, Regulation of hepA of Anabaena sp. strain PCC 7120 by elements 5' from the gene and by hepK, J Bacteriol 180 (1998) 4233-42.

[78] Rippka R, Stanier R, The effect of anaerobiosis on nitrogenase synthesis and heterocyst development by Nostocacean cyanobacteria, J Gen Microbiol 105 (1978) 83-94.

[79] Zhou R, Wolk CP, A two-component system mediates developmental regulation of biosynthesis of a heterocyst polysaccharide, J Biol Chem 278 (2003) 19939-46.

[80] Hagen KD, Meeks JC, Biochemical and genetic evidence for participation of DevR in a phosphorelay signal transduction pathway essential for heterocyst maturation in Nostoc punctiforme ATCC 29133, J Bacteriol 181 (1999) 4430-4.

[81] Ning D, Xu X, alr0117, a two-component histidine kinase gene, is involved in heterocyst development in Anabaena sp. PCC 7120, Microbiology 150 (2004) 447-53.

[82] Fan Q, Lechno-Yossef S, Ehira S, Kaneko T, Ohmori M, Sato N, Tabata S, Wolk CP, Signal transduction genes required for heterocyst maturation in Anabaena sp. strain PCC 7120, J Bacteriol 188 (2006) 6688-93.

[83] Lechno-Yossef S, Fan Q, Ehira S, Sato N, Wolk CP, Mutations in four regulatory genes have interrelated effects on heterocyst maturation in Anabaena sp. strain PCC 7120, J Bacteriol 188 (2006) 7387-95.

[84] Awai K, Lechno-Yossef S, Wolk CP, Heterocyst envelope glycolipids, in: Wada H, Murata N (Eds.) Lipids in Photosynthesis: Essential and Regulatory Functions, Springer Science + Business Media B.V. (2009) pp.179-202.

[85] Fan Q, Huang G, Lechno-Yossef S, Wolk CP, Kaneko T, Tabata S, Clustered genes required for synthesis and deposition of envelope glycolipids in Anabaena sp. strain PCC 7120, Mol Microbiol 58 (2005) 227-43.

[86] Awai K, Wolk CP, Identification of the glycosyl transferase required for synthesis of the principal glycolipid characteristic of heterocysts of Anabaena sp. strain PCC 7120, FEMS Microbiol Lett 266 (2007) 98-102.

[87] Staron P, Forchhammer K, Maldener I, Novel ATP-driven pathway of glycolipid export involving TolC protein, J Biol Chem 286 (2011) 38202-10.

[88] Fiedler G, Muro-Pastor AM, Flores E, Maldener I, NtcA-dependent expression of the $\operatorname{devBCA}$ operon, encoding a heterocyst-specific ATP-binding cassette transporter in Anabaena spp., J Bacteriol (2001) 3795-9.

[89] Muro-Pastor AM, Flores E, Herrero A, NtcA-regulated heterocyst differentiation genes hetC and $\operatorname{dev} B$ from Anabaena sp. strain PCC 7120 exhibit a similar tandem promoter arrangement, J Bacteriol (2009) 5765-74.

[90] Hebbar PB, Curtis SE, Characterization of $\operatorname{devH}$, a gene encoding a putative DNA binding protein required for heterocyst function in Anabaena sp. strain PCC 7120, J Bacteriol 182 (2000) 3572-81.

[91] Ramírez ME, Hebbar PB, Zhou R, Wolk CP, Curtis SE, Anabaena sp. strain PCC 7120 gene devH is required for synthesis of the heterocyst glycolipid layer, J Bacteriol 187 (2005) 2326-31.

[92] Shi L, Li JH, Cheng Y, Wang L, Chen WL, Zhang CC, Two genes encoding protein kinases of the HstK family are involved in synthesis of the minor heterocyst-specific glycolipid in the cyanobacterium Anabaena sp. strain PCC 7120, J Bacteriol 189 (2007) 5075-81. 


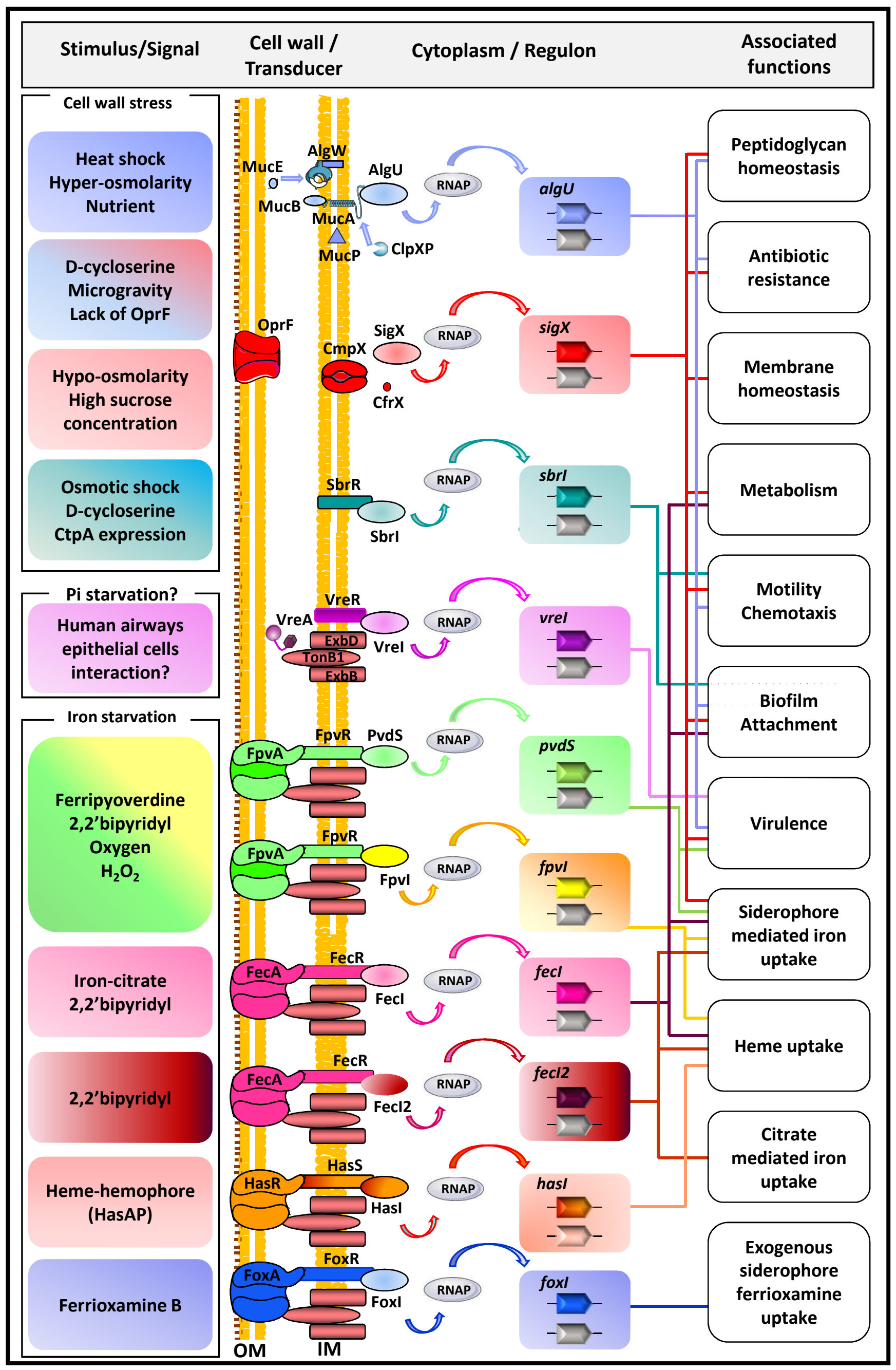


Figure 2. Mechanism of activation of AlgU (RpoE)

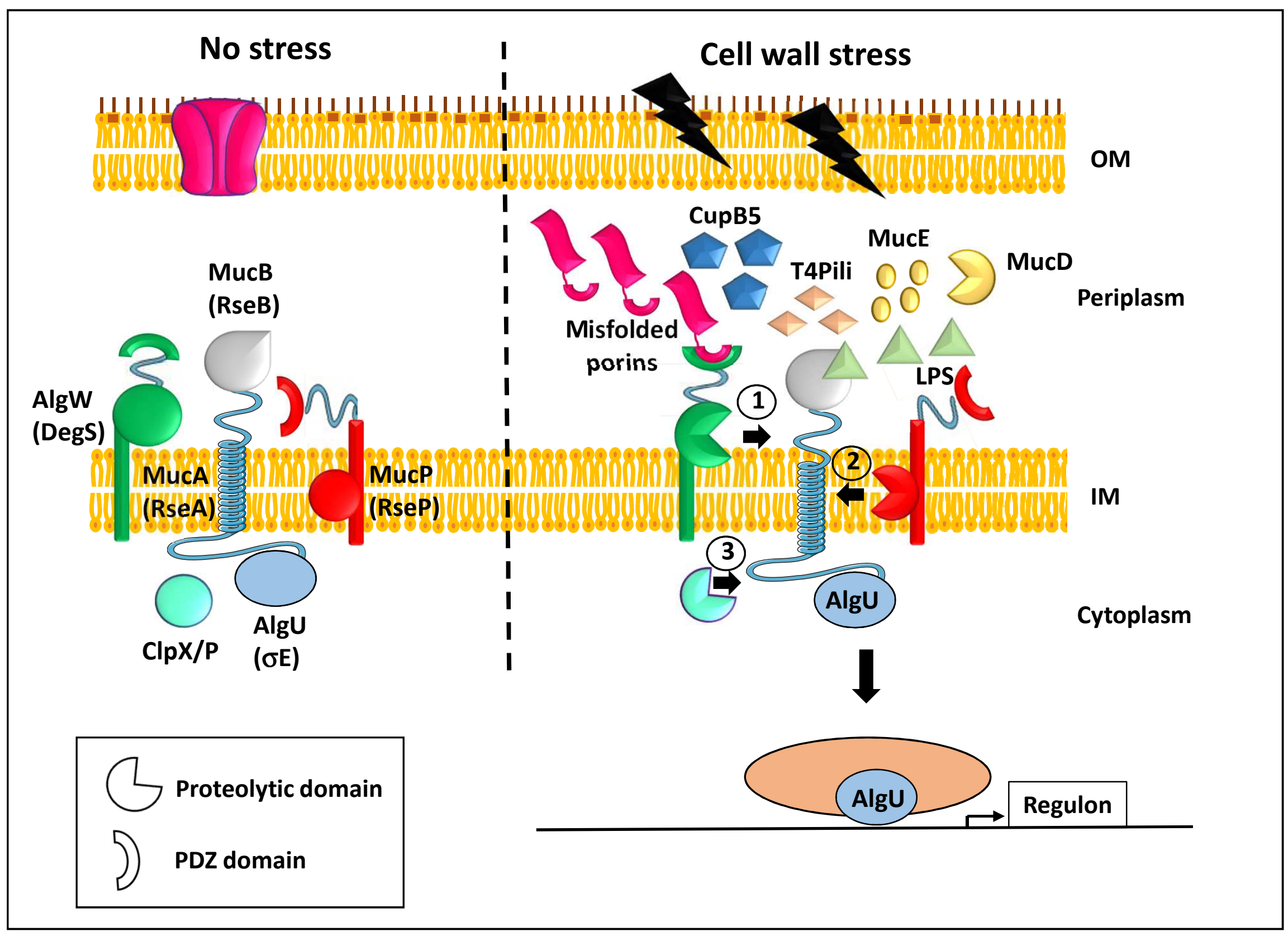




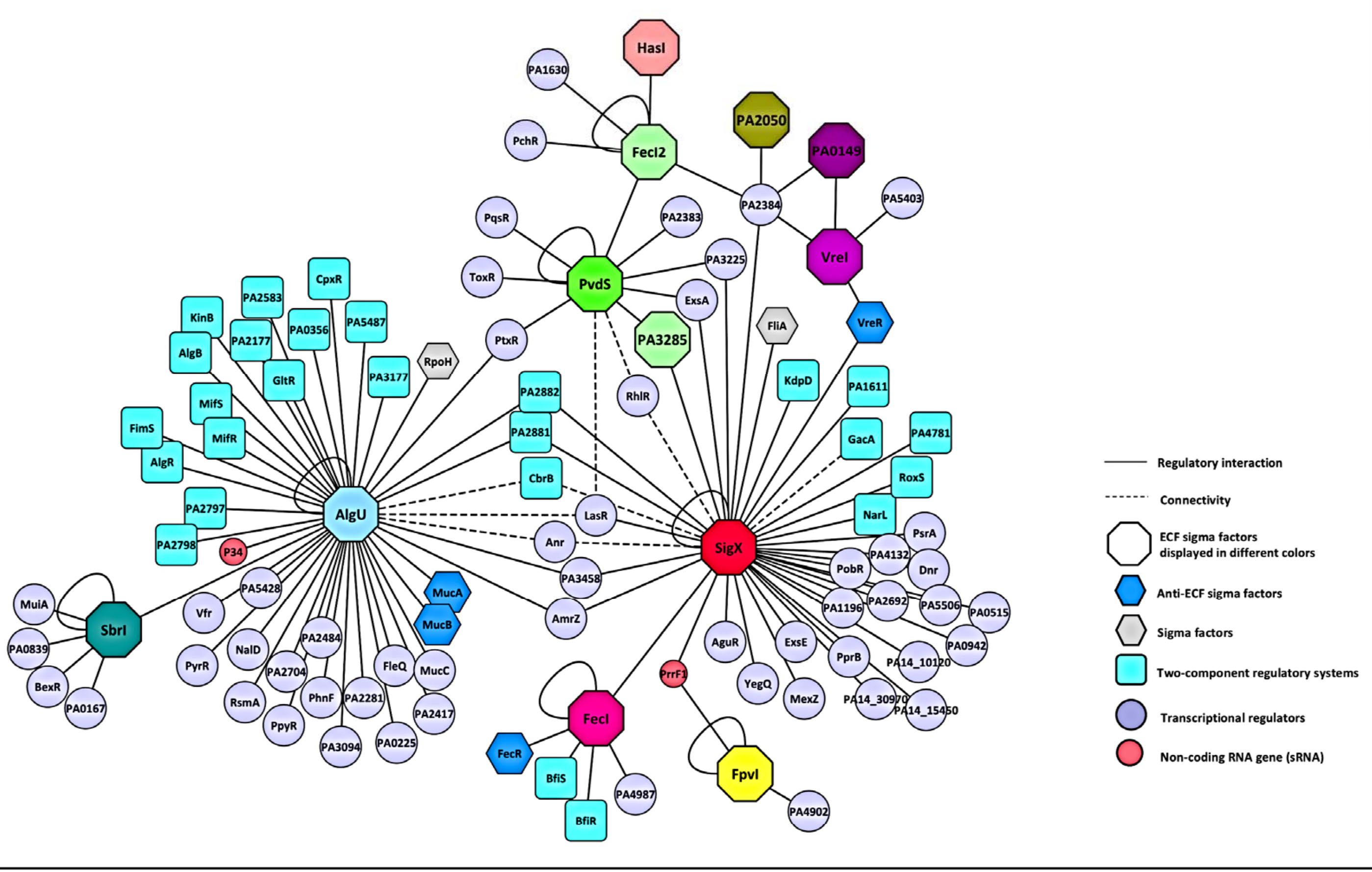


Figure 4: Regulators involved in ECF sigma factors expression

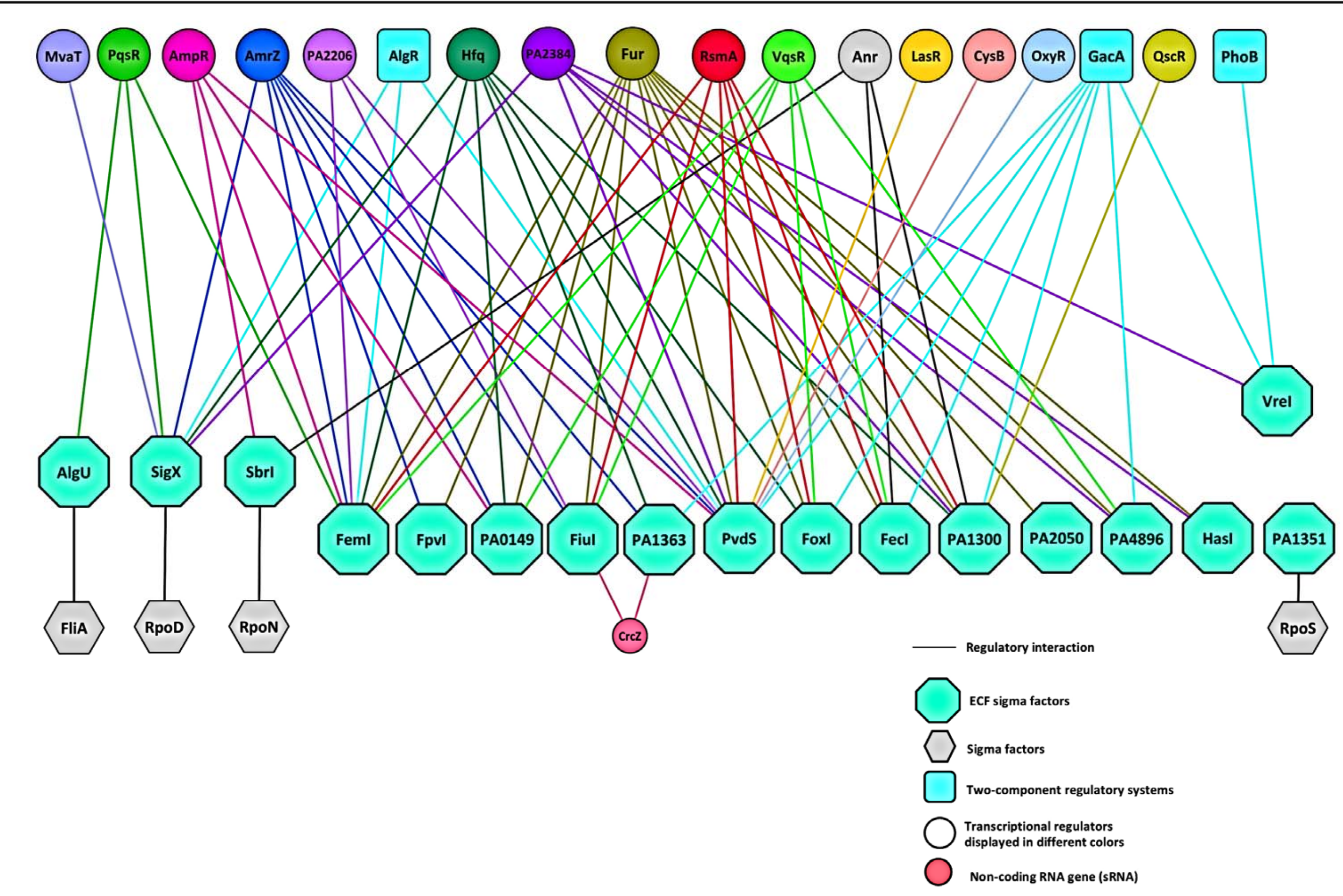


Figure 5. FpvA cell surface signaling

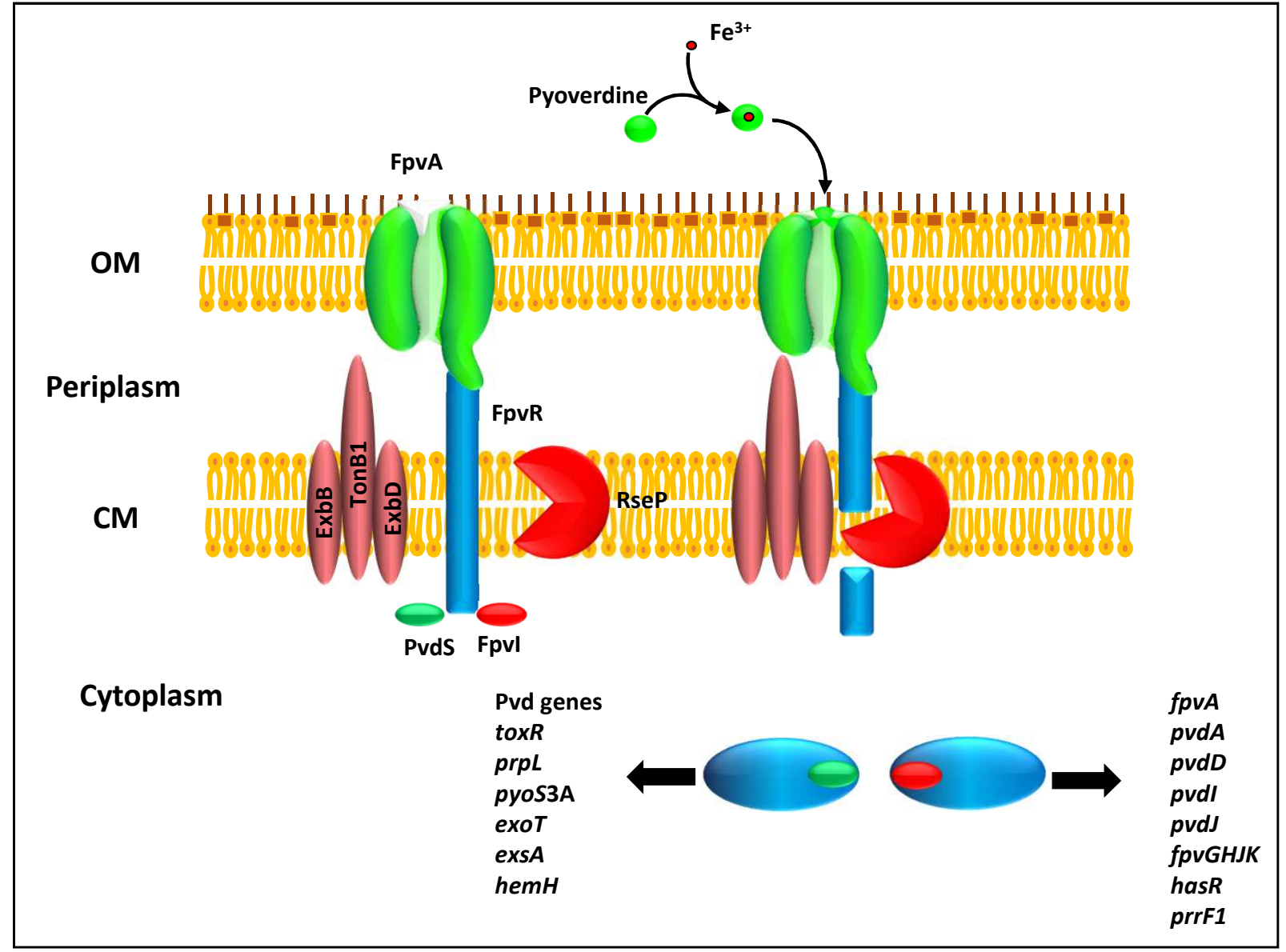


Figure 6: Pyoverdine cluster

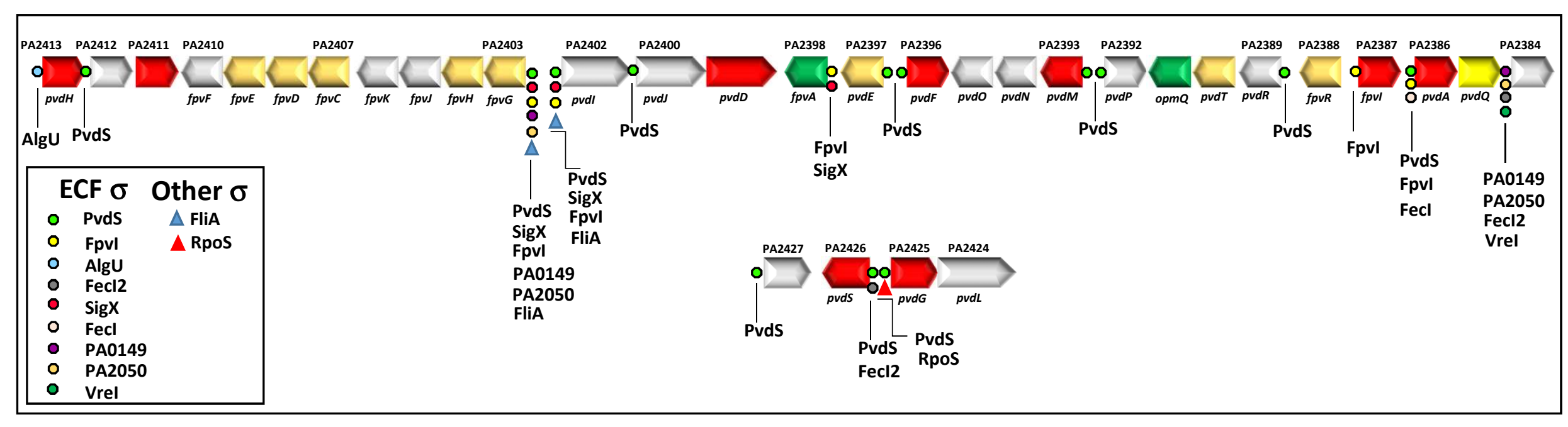




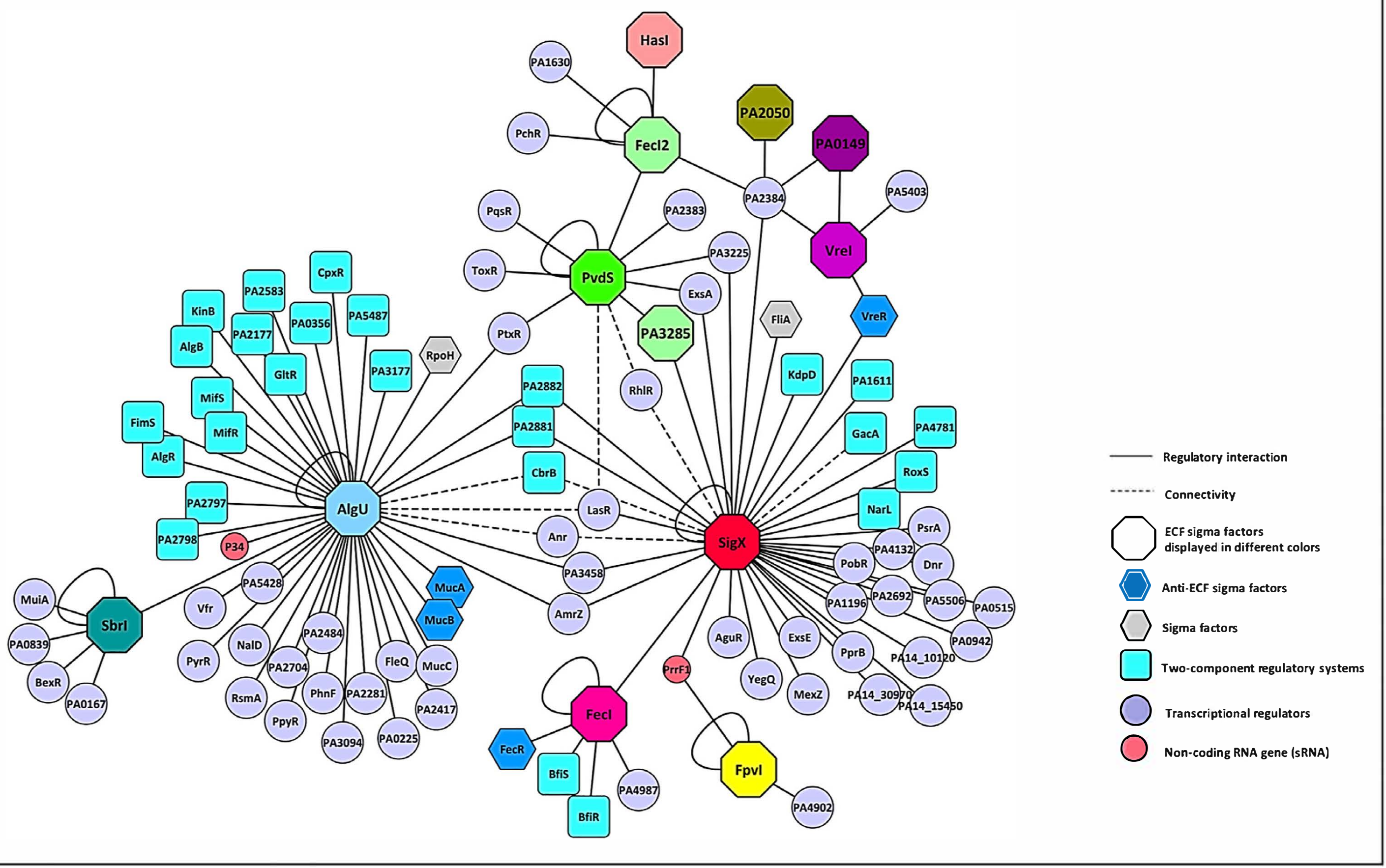

